Research Article

\title{
Permeability Characteristics of Water-Sand Seepage in Fracture by Experiment
}

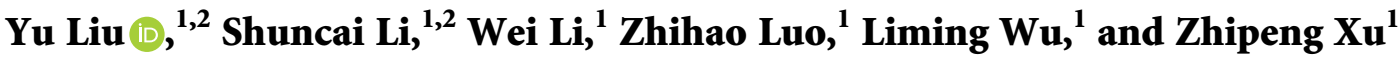 \\ ${ }^{1}$ School of Mechatronic Engineering, Jiangsu Normal University, Xuzhou 221116, China \\ ${ }^{2}$ State Key Laboratory of Coal Resources and Safety Mining, China University of Mining and Technology, Xuzhou 221116, China
}

Correspondence should be addressed to Yu Liu; 6020040051@jsnu.edu.cn

Received 10 April 2021; Revised 25 June 2021; Accepted 16 August 2021; Published 29 September 2021

Academic Editor: Zhigang Zhang

Copyright (C) 2021 Yu Liu et al. This is an open access article distributed under the Creative Commons Attribution License, which permits unrestricted use, distribution, and reproduction in any medium, provided the original work is properly cited.

Studies on the seepage characteristics of water-sand cracks are of great significance to reveal the mechanisms of water and sand inrush. Using a self-made water-sand fracture seepage test instrument, a water-sand seepage test was carried out, and the permeability of water and sand in the fracture was determined. The hysteresis characteristics of water-sand flow in the fracture were obtained after the required permeability was attained. The results show that the hysteresis curve changes from type I to type IV with the increase in sand particle size and concentration. The hysteresis parameters are described by the maximum hysteresis $G p^{*}$ and the hysteresis area $S$, both of which show an increasing trend with the increase in sand particle size and concentration; however, this increase is not synchronous. The average velocity and turbulent kinetic energy distribution of the water-sand fluid on the fracture cross section are greatly affected by the particle size and concentration of the volume of sand. This study can provide a reference for further study of water inrush from a shallow coal seam. Through simulation, it is found that the particle size has a great influence on the seepage velocity, and the influence near the side wall surface is greater than that in the middle position.

\section{Introduction}

Water and sand inrush is a serious menace to mine safety and needs to be understood well. The sand-bearing water layer that is always located above the coal seam is shown in Figure 1. Experimental and theoretical research was done to obtain the mechanism of water and sand inrush [1-4]. Analysis shows that the mechanism of interaction of water and sand is complicated, and the influencing factors include the channel of fracture, starting pressure gradient of water and sand particles, and concentration of sand and water.

Material flow in a smooth fracture may be described by a cubic relationship, but natural fractures are rough and the flow is difficult to measure, leading to much research [5-8]. During studies on the seepage in the fracture, many scholars found the permeability in the fracture to be non-linear [9-12]. Till recently, Forchheimer's law was used widely for modeling; in addition, the Reynolds number of the fracture flow was also discussed [13-15]. The Izbash law was further revised to account for roughness $[16,17]$ and the seepage in fracture related to surface roughness and fracture aperture [18-20]; this is difficult to determine given the lack of accurate characterization and measurement techniques because fracture geometries are heterogeneous and invisible. To measure the roughness of the fracture, many parameters were established to express it [21-24].

Du et al. [25] obtained the law of water and sand flow in the broken rock, and Liu et al. [26] obtained the permeability of water and sand in the fracture under different conditions. Sui et al. [27] obtained the law of dry sand migration and discussed the initial conditions of water and sand. Ma et al. [28] and Liu and Liu [29] obtained the water-sand flow from seepage to tube flow, and $\mathrm{Hu}$ et al. [30] further proved it.

On studying the water and sand flow, some new characteristics of the water and the flow in the fracture are discussed. Liu et al. [31] identified the phenomenon of hysteresis in the flow of water and sand, but the detailed characteristics were not discussed. Hysteresis was also found for the magnetic force and stress-strain fields, and similar laws were also found for gas permeability [31, 32]. Fan and 


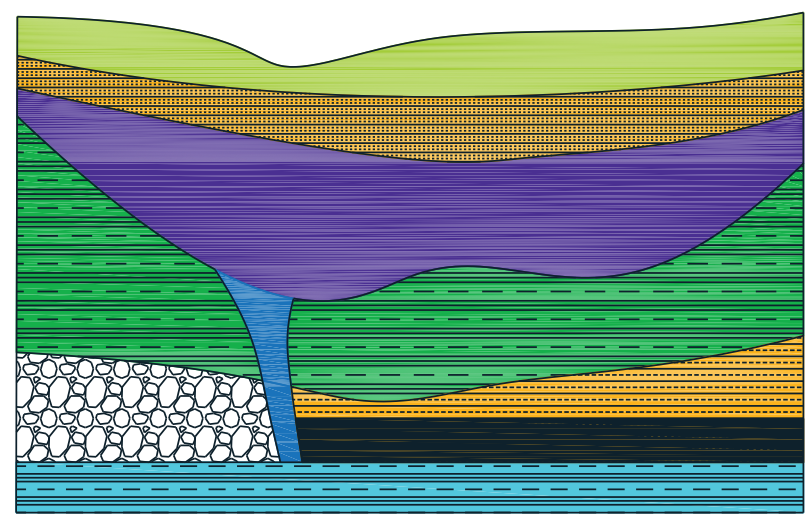

(a)

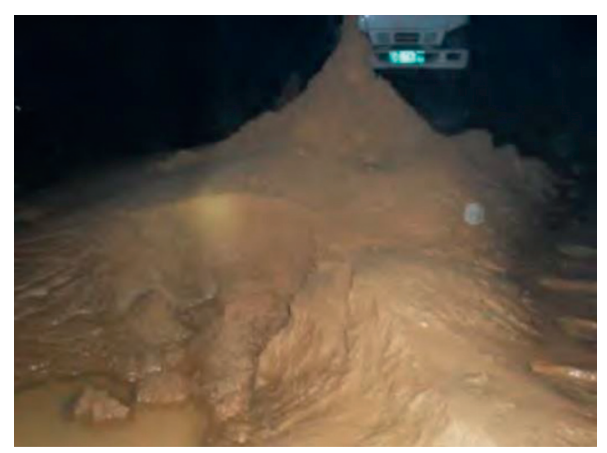

(b)

Figure 1: Water and sand inrush. (a) Schematic diagram. (b) Accident site [1].

Liu [33] obtained the permeability hysteresis during the cyclic loading-unloading. Hu et al. [34] and Duan et al. [35] obtained the permeability hysteresis and stress sensitivity coefficients on the loading path, which were higher than those on the unloading path.

Through analysis, the mechanism of water and sand transport has been recognized and elucidated. As the main transport channel, the fracture is the main channel for water and sand migration, but its migration rule is yet to be determined, resulting in the need for further analysis when water and sand flow through the fracture.

The purpose of this work is to identify the water infiltration characteristics of sand as the research object, use indoor testing to determine the hysteresis change characteristics of the fracture seepage of water and sand, and use numerical simulation to study the influence factors of the water and sand seepage field. This is of great significance to grasp the mechanism of water inrush and movement of sand.

\section{Test Principle and Method}

2.1. Test Materials. In this paper, the rock sample is sandstone from below $-265 \mathrm{~m}$ at the Luan mine in Shanxi, China, and the length of fracture is $L=125 \mathrm{~mm}$, the height is $h=75 \mathrm{~mm}$, and $b=0.25 \mathrm{~mm}, 0.5 \mathrm{~mm}, 0.75 \mathrm{~mm}$, and $1.0 \mathrm{~mm}$, as shown in Figure 2. The sand was taken from Lingshou County, Hebei Province, with four particle sizes: $0.092-0.138 \mathrm{~mm}, \quad 0.138-0.184 \mathrm{~mm}, \quad 0.184-0.230 \mathrm{~mm}$, and $0.230-0.276 \mathrm{~mm}$. Permeation tests were carried out at $20 \mathrm{~kg} /$ $\mathrm{m}^{3}, 40 \mathrm{~kg} / \mathrm{m}^{3}, 60 \mathrm{~kg} / \mathrm{m}^{3}$, and $80 \mathrm{~kg} / \mathrm{m}^{3}$, respectively.

2.2. Experimental Equipment and Steps. A set of experimental systems was designed and manufactured as shown in Figure 3, which consists of a mixing system of water and sand (1), water and sand loading system (2), data acquisition system (3), computer (4), and seepage apparatus (5).

The test steps were as follows:

(1) The test system was assembled according to Figure 3, and the sample was loaded. The leakage of the experiment system was tested.
(2) The sand particle with a diameter of $0.038 \sim 0.044 \mathrm{~mm}$ was placed into the mixing pool, and the sand concentration was $20 \mathrm{~kg} / \mathrm{m}^{3}$ at 1 cubic meter of water.

To control the motor speed, the flow and pressure under different rotational speeds were recorded while the fracture aperture was $0.75 \mathrm{~mm}$; the motor speed was varied as $200 \mathrm{r} / \mathrm{min}, 400 \mathrm{r} / \mathrm{min}, 600 \mathrm{r} / \mathrm{min}$, $800 \mathrm{r} / \mathrm{min}$, and $1000 \mathrm{r} / \mathrm{min}$. Different pressures and seepage velocities of the fracture were obtained using a paperless recorder. The sand concentration $\rho_{\mathrm{s}}$ in water was $40 \mathrm{~kg} / \mathrm{m}^{3}, 60 \mathrm{~kg} / \mathrm{m}^{3}$, and $80 \mathrm{~kg} / \mathrm{m}^{3}$, respectively.

(3) The flow and pressure under different particle diameters $\quad(0.038 \sim 0.044 \mathrm{~mm}, \quad 0.061 \sim 0.080 \mathrm{~mm}$, $0.090 \sim 0.109 \mathrm{~mm}$, and $0.120 \sim 0.180 \mathrm{~mm}$ ) were recorded during the different rotational speeds. For ease of calculation, we consider the arithmetic mean of each range of the particle diameter, $0.041 \mathrm{~mm}, 0.071 \mathrm{~mm}$, $0.100 \mathrm{~mm}$, and $0.150 \mathrm{~mm}$.

(4) According to equation (1), the permeability parameters can be obtained by least square fitting [36].

$$
\frac{\mu_{e}}{k_{e}} \frac{\mathrm{Q}}{b h}+m \beta\left(\frac{\mathrm{Q}}{\mathrm{Q}}\right)^{2}=-\frac{\mathrm{d} p}{\mathrm{~d} l},
$$

where $\mu_{e}$ is the effective viscosity, $k_{e}$ is the effective permeability, $\beta$ is the non-Darcy factor, $Q$ is the flow, and $p$ is the pressure.

\section{Results and Discussion}

3.1. Influence of Fracture Aperture on the Permeability. Let $I_{e}=k_{e} / \mu_{e}$, and the permeability parameters of water and sand in the fracture are obtained as shown in Figure 4.

The mass concentration of sand is $20 \mathrm{~kg} / \mathrm{m}^{3}$ and $40 \mathrm{~kg} /$ $\mathrm{m}^{3}$. The fracture openings are divided into five grades: $0.5 \mathrm{~mm}, 0.75 \mathrm{~mm}, 1.00 \mathrm{~mm}, 1.25 \mathrm{~mm}$, and $1.50 \mathrm{~mm}$. The data from the pressure transmitter and flow sensor are collected after the pressure and flow of the seepage system are 


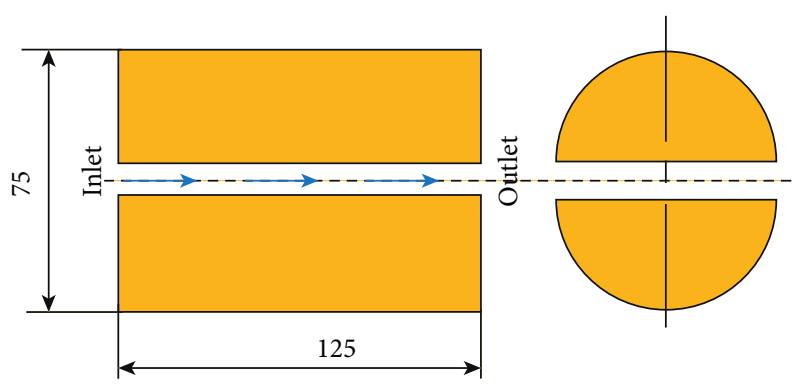

FIGURE 2: Fracture specimen.

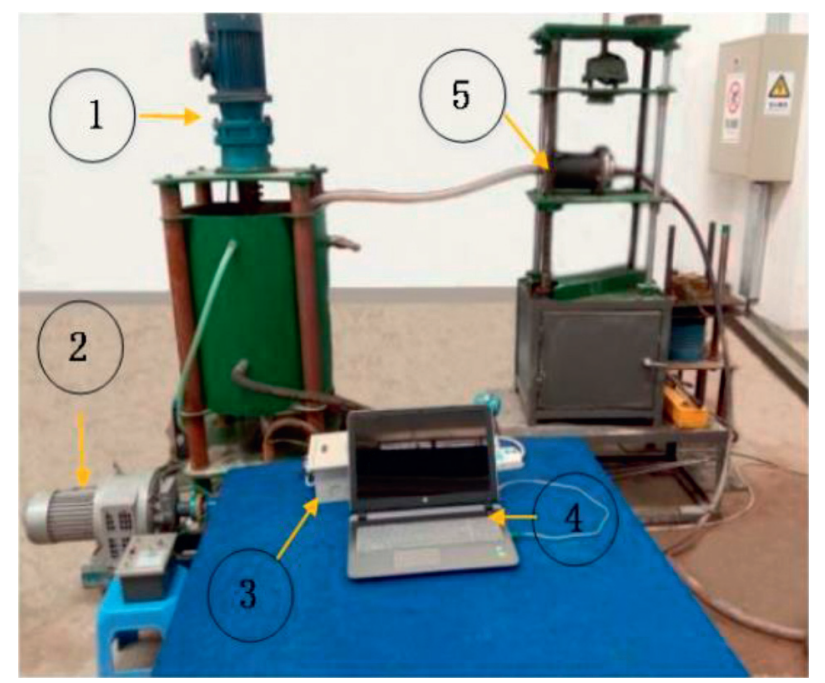

FIGURE 3: Water injection system to measure hydraulic extrusion: 1, mixing system; 2 , sewage pump; 3 , acquisition card; 4 , computer; 5 , seepage instrument.

stabilized. The seepage test results for sand particle size 0.038 $\sim 0.044 \mathrm{~mm}$, sand mass concentration $20 \mathrm{~kg} / \mathrm{m}^{3}$ and $40 \mathrm{~kg} /$ $\mathrm{m}^{3}$, and joint roughness coefficient (JRC) $2-4$, respectively.

From Figure 4, the effective fluidity of water and sand in the fracture increases with the width of fracture, and the non-Darcy factor decreases with the width of the fracture.

Fracture aperture has considerable influence on the permeability [37]; many scholars studied it with reference to water and gas $[38,39]$ and modified the cubic law or the Izbash law. In this study, we discussed the effective fluidity, which depends on the shape of the fracture and the characteristics of the fluid and thus differs for water and gaseous substances. The obtained results could be fitted using the cubic law.

\subsection{Influence of Fracture Roughness on Permeability.} Table 1 shows the changes in the effective fluidity and nonDarcy flow factor $\beta$ of water-sand mixture seepage with the roughness. Permeability of water and sand in the fracture is obtained by changing fracture roughness and mass concentration. The relationship between $I_{e}, \beta$, and JRC is an exponential function.

Along with the increase in the aperture and $J R C$ of fracture, the effective fluidity increases, and non-Darcy factor decreases. In the range of the fracture aperture $0.5 \mathrm{~mm} \sim 1.5 \mathrm{~mm}$ and $J R C 2 \sim 8$, the field of effective fluidity is $10^{-8} \sim 10^{-5} \mathrm{~m}^{n+2} \cdot \mathrm{s}^{2-n} / \mathrm{kg}$, and the non-Darcy factor $\beta$ is $10^{5} \sim 10^{8} \mathrm{~m}^{-1}$.

Hu et al. [40] concluded that the roughness will influence the distribution of the concentration and decrease the effective dispersion coefficient. Peng et al. [41] discovered that an increase in fracture roughness and concentrations will cause a decrease in the Darcy permeability coefficient. Yu and $\mathrm{Li}$ [42] discussed the roughness and the relationship between the solute transport curve and the maturity of the dominant channel. Here, we discussed water and sand flow through the fracture, and effective fluidity $I_{e}=K_{e} / \mu_{e}$ was introduced, where $K_{e}$ is the permeability of water and sand in fracture and $\mu_{e}$ is the viscosity of water and sand. It is a new method to determine the common influence characteristics of water and sand in the fracture.

3.3. Variation of Hysteresis Characteristics. The fracture aperture is $0.75 \mathrm{~mm}$, and the ratio of the fracture aperture to average particle size was $2.7: 1$. Seepage tests are carried out step by step. In Figure 5, there is no one-to-one correspondence between the pressure gradient and seepage velocity in the two stages of the rise and fall of the pressure gradient. 


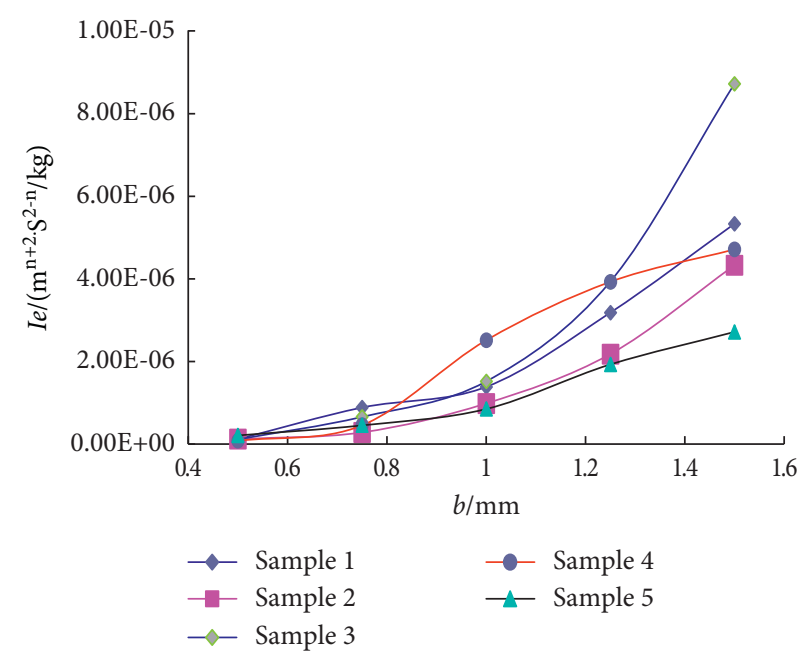

(a)

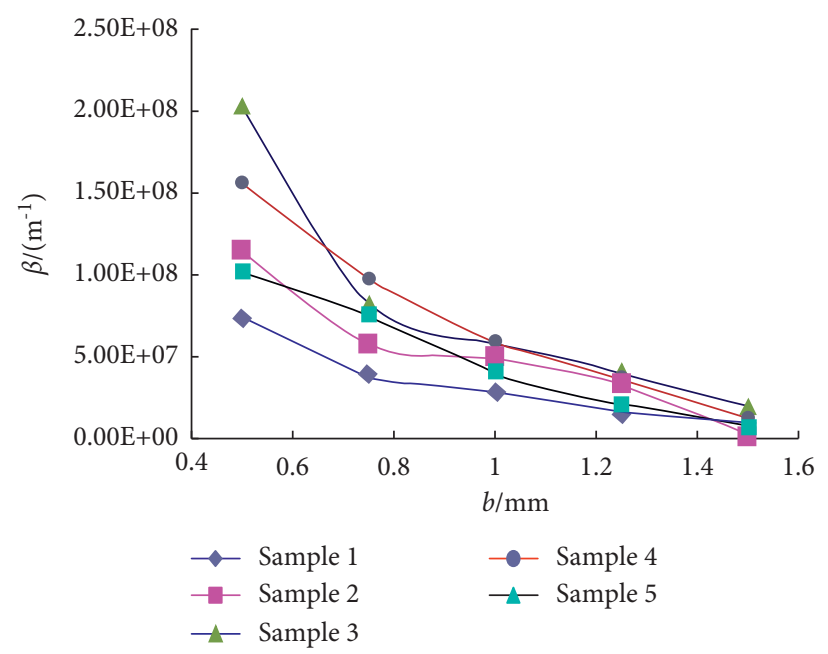

(b)

FiguRE 4: Curves of permeability parameters changing with the aperture at $d_{s}=0.038 \sim 0.044 \mathrm{~mm}$ and $\rho s=20 \mathrm{~kg} / \mathrm{m}^{3}$. (a) Curve of $I_{e^{-}} b$ at $\mathrm{JRC}=2 \sim 4$. (b) Curve of $\beta$-b at JRC $=2 \sim 4$.

TABLE 1: Fitted equations of permeability parameters changing with $J R C$ at $d_{s}=0.061 \sim 0.080 \mathrm{~mm}$.

\begin{tabular}{ccccc}
\hline Number & $\rho_{s}\left(\mathrm{~kg} / \mathrm{m}^{3}\right)$ & Parameter of permeability & Fitting equations & Coefficients \\
\hline \multirow{2}{*}{20} & $I_{e}$ & $I_{e}=6.40 \times 10^{-5} e-0.38 \mathrm{JRC}$ & 0.9979 \\
& \multirow{2}{*}{40} & $I_{e}$ & $\beta=8.10 \times 10^{4} e 0.45 \mathrm{JRC}$ & 0.9943 \\
2 & $\beta$ & $\mathrm{Ie}=8.08 \times 10^{-6} e-0.35 \mathrm{JRC}$ & 0.9246 \\
& & $I_{e}$ & $\beta=2.41 \times 10^{6} e 0.32 \mathrm{JRC}$ & 0.9946 \\
3 & \multirow{2}{*}{60} & $\beta$ & $I_{e}=3.75 \times 10^{-6} e-0.38 \mathrm{JRC}$ & 0.9004 \\
& \multirow{2}{*}{80} & $I_{e}$ & $I_{e}=5.36 \times 10^{-6} e-0.44 \mathrm{JRC}$ & 0.9763 \\
4 & $\beta$ & $\beta=2.15 \times 10^{6} e 0.43 \mathrm{JRC}$ & 0.9871 \\
\end{tabular}

With the increase and decrease of the pressure gradient, the pressure gradient and seepage velocity form a closed curve in plane coordinates. During the increase and decrease of the pressure gradient, four hysteresis curves are obtained. The complete hysteresis curve is divided into two parts: lift section $\mathrm{OAB}$ and return section $\mathrm{BA}$ and $\mathrm{O}$. The lift curve and return curve of the type I curve intersect, the type II curve is similar to the hysteresis curve, the lift curve and return curve of type III curve coincide partly, and the lift curve and return curve of type IV curve have no coincidence point in the entire process.

With the increase in sand particle size and concentration, the hysteresis curve composed of the pressure gradient and seepage velocity gradually changes from type I to type IV, as shown in Tables 2 and 3.

The hysteresis curves of type I, II, III, and IV can be transformed from the former to the latter with the increase in sand particle size and concentration in Tables 2 and 3. The reason is that there are many movement patterns of watersand flow in fractures, such as single-phase flow (there is no relative velocity between sand and water), two-phase flow (there is relative velocity between sand and water), and slug flow (there is one or more interface between sand and water). The hysteresis curve changes with the change in particle size and concentration of sand.
3.4. Influence of Sand Particle Size on Hysteresis Characteristics. To analyze the influence of sand particle size on the hysteresis parameters of the type IV hysteresis curve, the maximum hysteresis of seepage velocity-pressure gradient hysteresis curve and hysteresis area $S$ of four groups of samples are summarized in Figure 6.

Figure 6 shows that the maximum hysteresis of the velocity-pressure gradient hysteresis curve of type IV watersand flow tends to increase with the increase in sand particle size. The maximum hysteresis of the hysteresis curve increases slowly when the sand particle size is $0.115 \mathrm{~mm} \sim 0.161 \mathrm{~mm}$ and $0.207 \mathrm{~mm} \sim 0.253 \mathrm{~mm}$. As the hysteresis curve is $0.161 \mathrm{~mm} \sim 0.207 \mathrm{~mm}$, the maximum hysteresis increases rapidly and approximates a linear growth.

3.5. Influence of Sand Concentration on Hysteresis Characteristics. The fracture aperture $b=0.5 \mathrm{~mm}$, sand particle size $d_{S}=0.230 \mathrm{~mm} \sim 0.276 \mathrm{~mm}$, and sand mass concentration $p_{s}$ were selected as variables. The hysteresis curves of fracture seepage were studied by setting four different water-sand mixtures of $20 \mathrm{~kg} / \mathrm{m}^{3}, 40 \mathrm{~kg} / \mathrm{m}^{3}, 60 \mathrm{~kg} /$ $\mathrm{m}^{3}$, and $80 \mathrm{~kg} / \mathrm{m}^{3}$. Compared with the effect of particle size on seepage, the effect of concentration on permeability is 


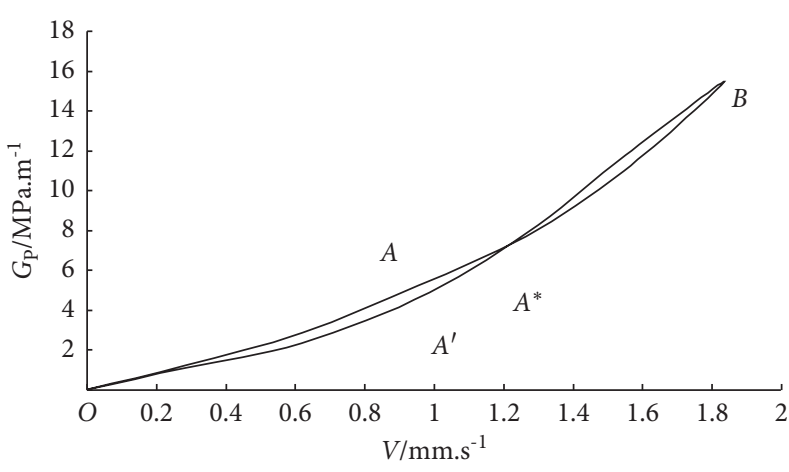

(a)

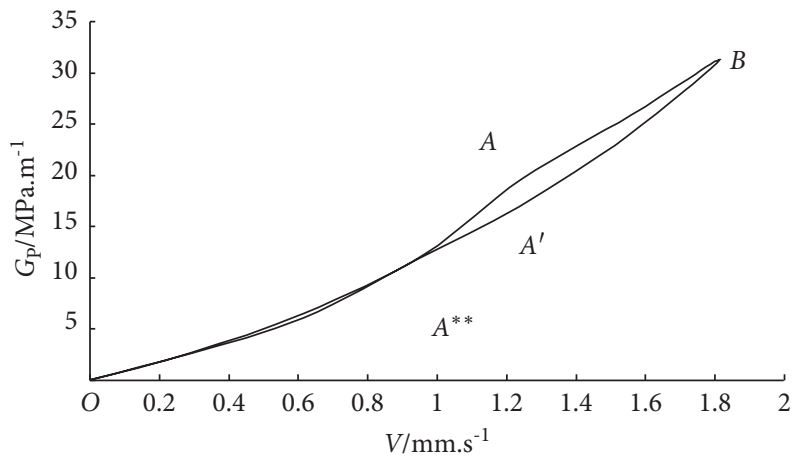

(c)

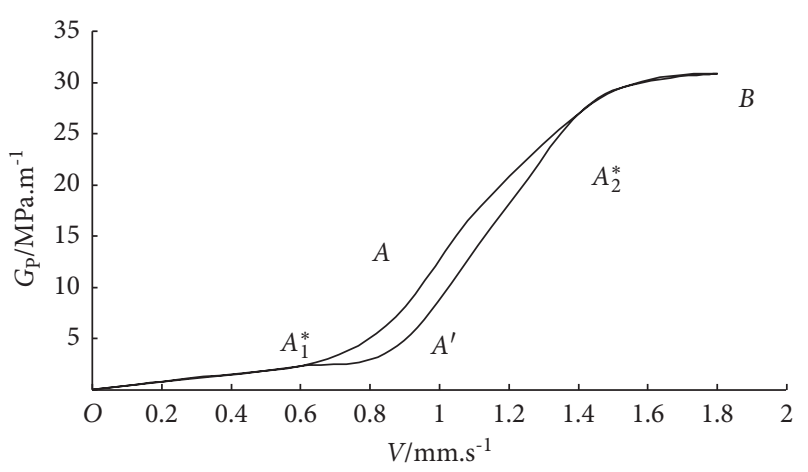

(b)

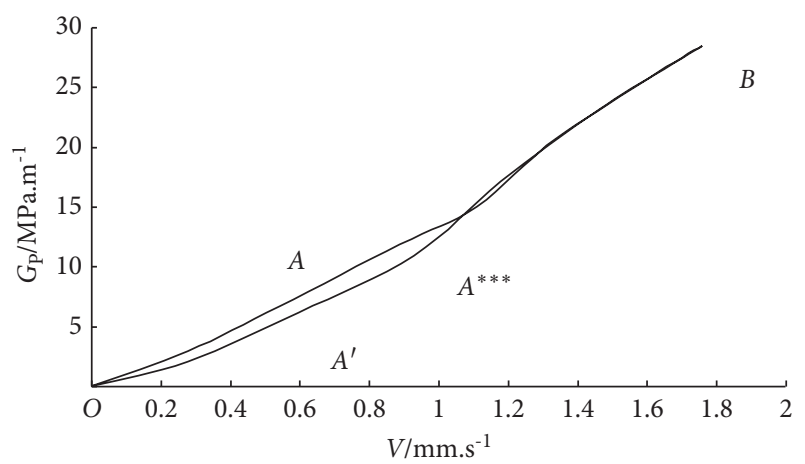

(d)

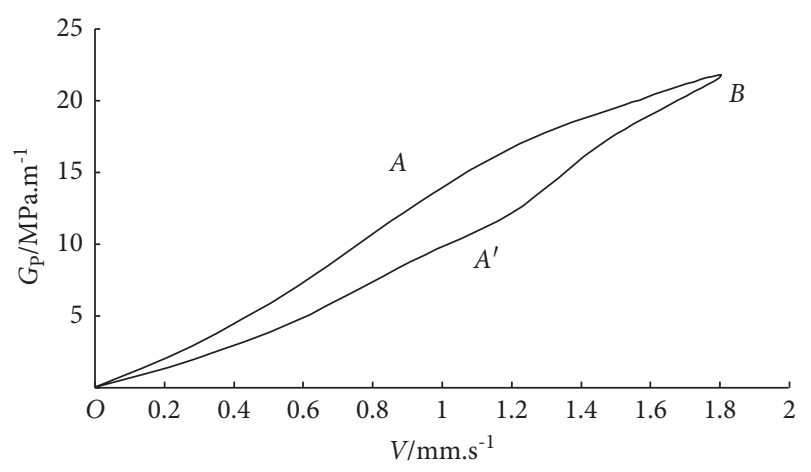

(e)

FIgURE 5: Four types of hysteresis curves. (a) I curve. (b) II curve. (c) $\mathrm{III}_{1}$ curve. (d) $\mathrm{III}_{2}$ curve. (e) IV curve.

TABLe 2: Typical shapes and conditions of hysteresis curve at $b=0.75 \mathrm{~mm}$.

\begin{tabular}{lcccc}
\hline$\left(\mathrm{kg} / \mathrm{m}^{3}\right)$ & & & $d_{s}(\mathrm{~mm}) \rho_{s}$ & \\
\\
20 & $0.092 \sim 0.138$ & $0.138 \sim 0.184$ & $0.184 \sim 0.230$ & III \\
40 & I & II & III & III \\
60 & I & II & III & III \\
80 & II & II & III & IV \\
\hline
\end{tabular}

more intuitive. Compared with the concentration, the particle size varies between $0.138 \sim 0.184 \mathrm{~mm}$ and $0.184 \sim 0.230 \mathrm{~mm}$, but the effect of concentration on hysteresis basically maintains a similar linear relationship.

The hysteresis curves under different particle sizes are shown in Figure 7. The maximum hysteresis of the velocitypressure gradient hysteresis curve of type IV water-sand seepage increases with the increase in sand concentration. When the sand concentration ranges from $20 \mathrm{~kg} / \mathrm{m}^{3}$ to $40 \mathrm{~kg} / \mathrm{m}^{3}$ and $60 \mathrm{~kg} / \mathrm{m}^{3}$ to $80 \mathrm{~kg} / \mathrm{m}^{3}$, the hysteresis area of the hysteresis curve increases linearly, but the maximum hysteresis increases slowly.

Loading and unloading cycles have a significant impact on the permeability hysteresis of the samples [35, 43], and 
TABLE 3: Typical shapes and conditions of hysteresis curve at $b=1.25 \mathrm{~mm}$.

\begin{tabular}{|c|c|c|c|c|}
\hline \multirow{2}{*}{$\left(\mathrm{kg} / \mathrm{m}^{3}\right)$} & \multicolumn{4}{|c|}{$d_{s}(\mathrm{~mm}) \rho_{s}$} \\
\hline & $0.092 \sim 0.138$ & $0.138 \sim 0.184$ & $0.184 \sim 0.230$ & $0.230 \sim 0.276$ \\
\hline 20 & I & I & I & II \\
\hline 40 & I & II & II & II \\
\hline 60 & I & II & III & III \\
\hline 80 & II & III & IV & IV \\
\hline
\end{tabular}

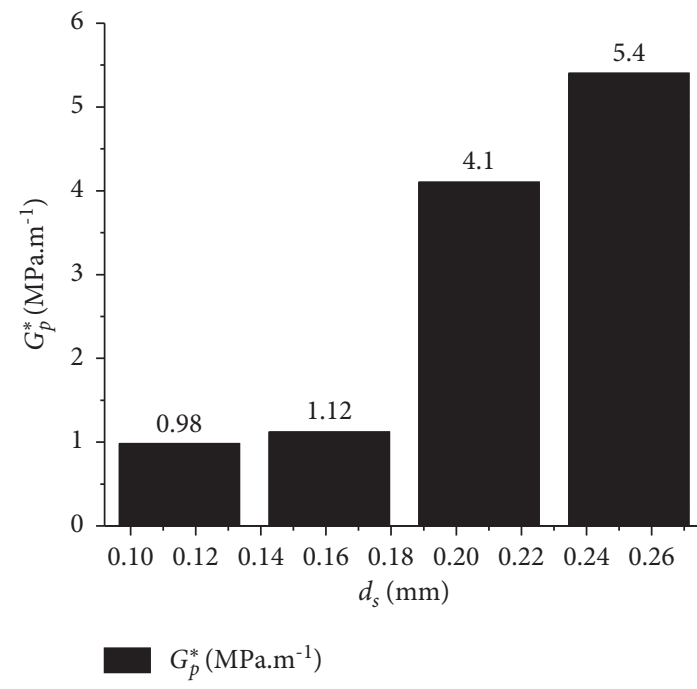

(a)

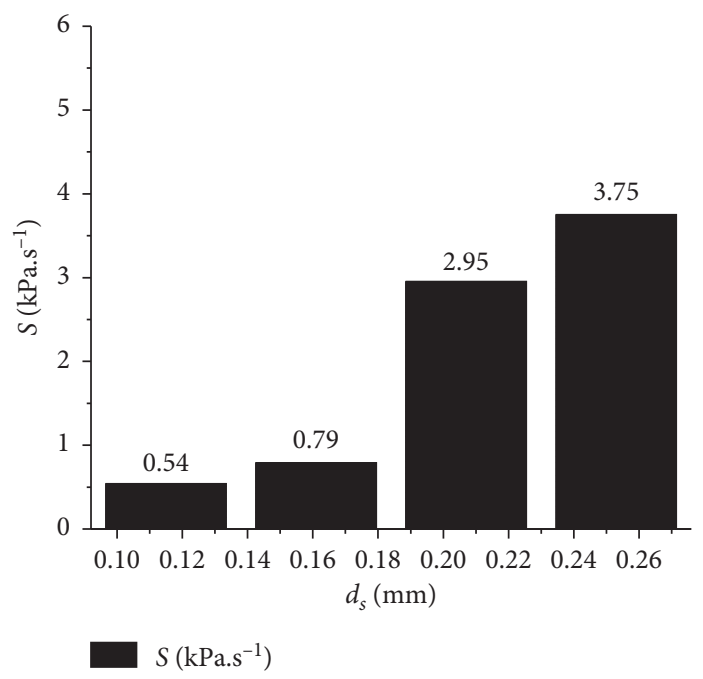

(b)

Figure 6: Hysteresis indicators of type IV hysteresis curves under different sand particle sizes at $b=0.5 \mathrm{~mm}$ and $\rho=80 \mathrm{~kg} / \mathrm{m}^{3}$. (a) Maximum hysteresis. (b) Hysteresis area.

the hysteresis effect is more significant under triaxial stress conditions than that under true-triaxial stress [44]. The size effect is an important factor to be analyzed, and in general, larger sizes have greater hysteresis [45].

In this study, two new parameters are introduced: the first is the maximum hysteresis and the second is the hysteresis area, which is more clearly stated. The water and sand in the fracture exhibit a similar trend: with the increase of particle size and concentration, the hysteresis shows an increasing trend, but the process is very non-linear.

\section{Simulation of the Water and Sand Flow in Fracture}

4.1. Velocity of Water and Flow in the Fracture. Figure 8 shows the velocity cloud map when the crack inlet velocity is $0.869 \mathrm{~m} / \mathrm{s}$ and $t=0.27 \mathrm{~s}$. As can be seen from Figure 8(a), the velocity distribution changes dramatically when the fluid enters the fracture passage through the fracture inlet. The flow in the fracture can be roughly divided into two parts. The roughness of the fracture may lead to turbulence, resulting in the decrease in the velocity of water-sand flow, and the velocity in the middle of the water-sand flow is obviously greater than that near the fracture wall. One part is the main flow between $X_{2}=1 \mathrm{~mm}$ and $X_{2}=1.8 \mathrm{~mm}$. The velocity ranges from $2.21 \mathrm{~m} / \mathrm{s}$ to $3.16 \mathrm{~m} / \mathrm{s}$, and there are many discontinuous high-speed areas. The main flow curve is generated at the sharp angle of the fracture, and the curve is distributed unevenly along the flow direction. The other part is the vortex area at the concave angle of the fracture, and the fluid velocity in the vortex center and the wall boundary layer area is low. As $X$ increases, the velocity of water and sand decrease.

As can be seen from Figure 8(b), the absolute pressure gradient-seepage velocity curve of two-phase fracture watersand flow obtained by numerical simulation is consistent with the curve obtained by the test, and there is a non-linear relationship between the absolute pressure gradient and seepage velocity. The numerical simulation results are smaller than the experimental results, and the relative error is between $18.5 \%$ and $46.7 \%$. It should be noted that the absolute errors in the numerical simulation results and experimental results are close at different flow rates, while the relative errors decrease with the increase in flow rates.

4.2. Variation of Sand Particle Size. The influence of sand particle size on the fracture flow field is discussed under the conditions of sand particle density of $2650 \mathrm{~kg} / \mathrm{m}^{3}$ and sand particle volume concentration of $4.06 \%$. Figure 9 shows the absolute value of pressure gradient-sand particle size curve. Water and sand flow in rough fractures. 


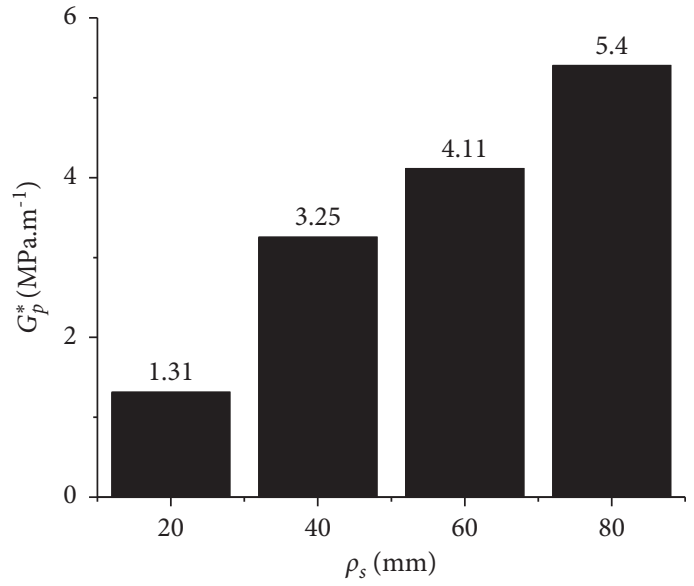

$G_{p}^{*}\left(\mathrm{MPa}^{-1}\right)$

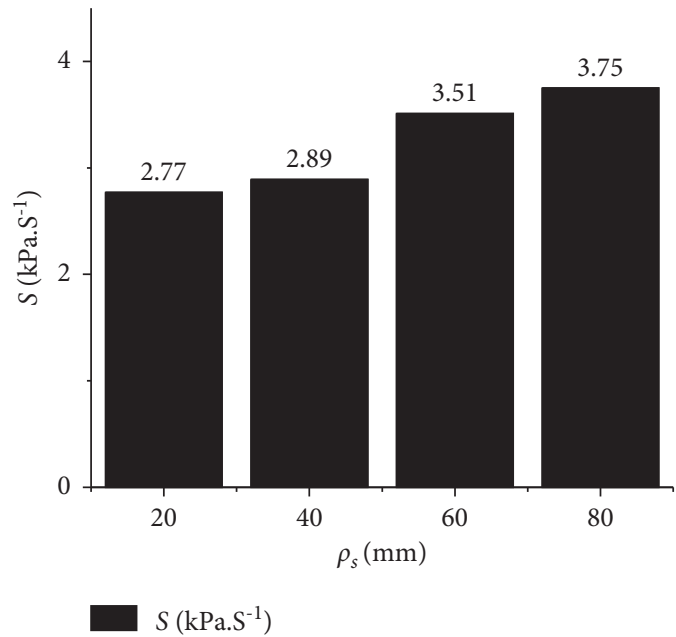

(b)

FIgURE 7: Hysteresis parameters of different concentrations. (a) Maximum hysteresis. (b) Hysteresis area.

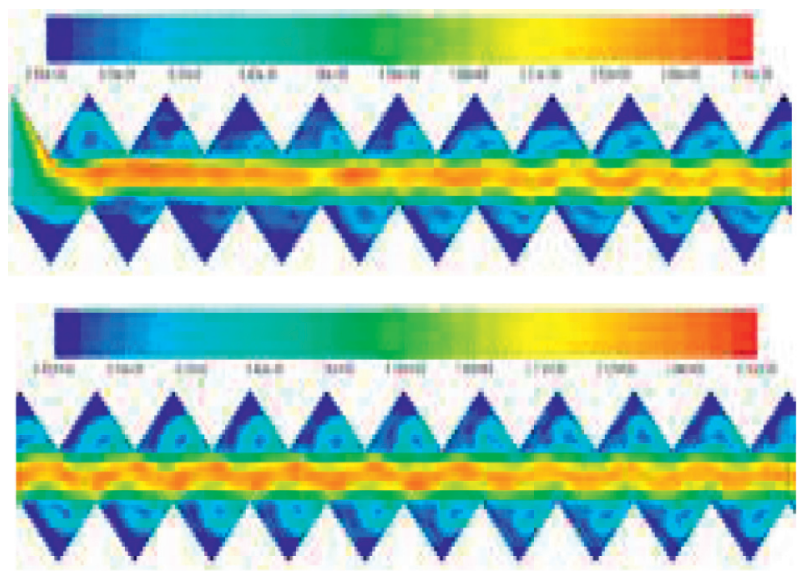

(a)

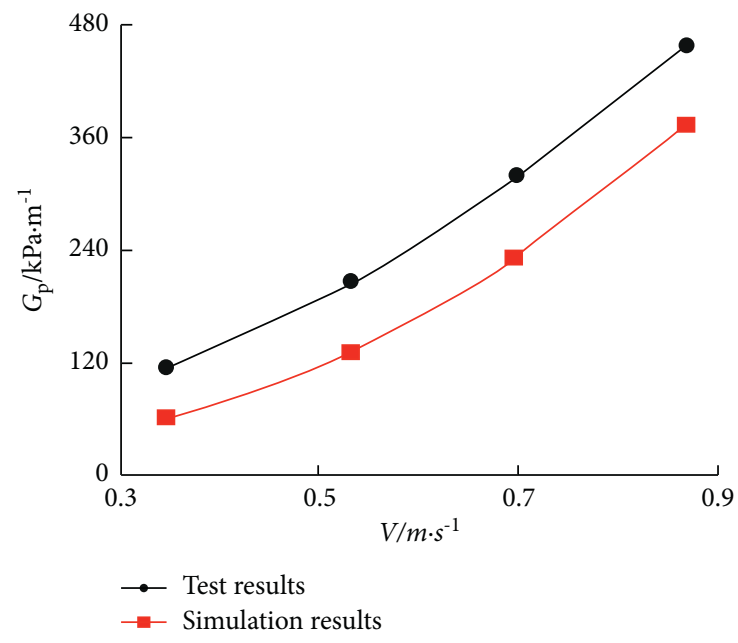

(b)

Figure 8: Nephogram of velocity. (a) $0-20 \mathrm{~mm}$ and $20-40 \mathrm{~mm}$ start of fracture. (b) Comparison of curves of $G_{p}-V$.

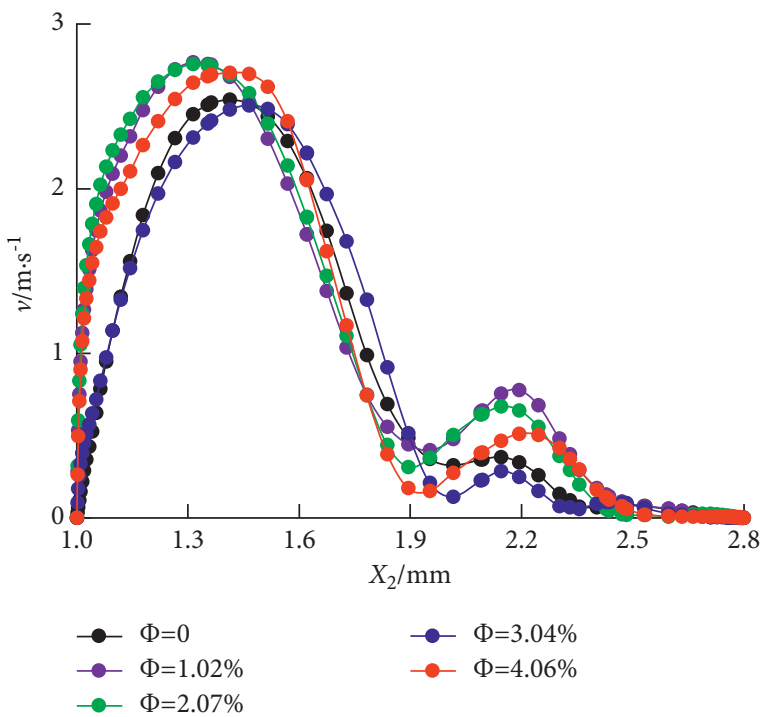

FIGURE 9: Uniform velocity distribution of continuous phase fluid on cross section of rough fracture. 
The absolute value of the pressure gradient is the largest when the sand particle size is 0 , and the absolute value of the pressure gradient is the smallest when the sand particle size is $0.12 \mathrm{~mm}$; the absolute value of the pressure gradient appears to be minimum when the sand particle size is $0.01 \mathrm{~mm}$. At $0.04 \mathrm{~mm}$, the absolute value of the pressure gradient decreases monotonously with the increase in sand particle size. This shows that water and sand flow in the rough fracture. When the sand particle size is small, pressure loss increases with the increase in sand particle size; when the sand particle size is large, pressure loss decreases with the increase in sand particle size.

In Figure 9, water and sand flow in the rough fractures, and the uniform velocity distribution of the continuous fluid phase on the fracture cross section is greatly affected by the volume concentration of sand particles. On the cross section $X_{1}=50.5 \mathrm{~mm}$, the time-averaged velocity distribution is no longer symmetric, but the peak value is in the vicinity of the central line $X_{2}=1.4 \mathrm{~mm}$, with multiple extremum points. The mean velocity changed dramatically with the volume fraction of sand particles near the wall surface. In other locations, the time-averaged velocity also varies with the velocity, but it is not significant near the wall surface. This indicates that the influence of sand particle volume fraction on the watersand two-phase flow in the section $X_{1}=50.5 \mathrm{~mm}$ mainly occurs near the wall surface.

\section{Conclusion}

(1) Permeability of water and sand flow in fracture is tested by the homemade experimental apparatus, effective fluidity distribution is in $10^{-8} \sim 10^{-5}$ $\mathrm{m}^{n+2} \cdot \mathrm{s}^{2-n} / k$, and non-Darcy factor $\beta$ distribution is $10^{5} \sim 10^{8} \mathrm{~m}^{-1}$.

(2) With the increase in sand particle size and sand mass concentration, the maximum hysteresis of the velocity gradient hysteresis curve increases linearly.

(3) The structure of the rough fracture surface results in a certain randomness in the water-sand seepage field. The reason is that water and sand are deposited in the rough fracture surface, resulting in a complex relationship among the rough fracture surface, water, and sand and a non-unique relationship between the pressure gradient and water-sand seepage velocity.

(4) When the sand particle size is small, the pressure loss increases with the increase in the sand particle size. When the sand particle size is large, the pressure loss decreases with the increase in the sand particle size. The distribution of the mean velocity and turbulent kinetic energy of the fluid on the fracture cross section is greatly affected by the size of the sand particle, which is indicated by the deviation of the position of the extreme point.

(5) Through the simulation, the absolute errors in the numerical simulation results and experimental results are close at different flow rates, while the relative errors decrease with the increase in flow rates.

\section{Data Availability}

The experimental data used to support the findings of this study are included within the article.

\section{Conflicts of Interest}

The authors declare that there are no conflicts of interest regarding the publication of this paper.

\section{Acknowledgments}

This research was funded by the National Natural Science Foundation of China (52034007), Xuzhou Science and Technology Project (KC18118), and the Research Fund of the State Key Laboratory of Coal Resources and Safe Mining, CUMT (SKLCRSM18KF009 and SKLCRSM19KF013).

\section{References}

[1] J. Yang, Z. Wu, H. Li, B. Zhang, and W. Ji, "Simulation experiment and influence factors analysis of collapsing of water and sand in shallow thin bedrock face," Coal Science and Technology, vol. 48, 2019, https://kns.cnki.net/kcms/detail/11. 2402.TD.20191205.1129.002.html.

[2] Y. Liang, W. Sui, and J. Qi, "Experimental investigation on chemical grouting of inclined fracture to control sand and water flow," Tunnelling and Underground Space Technology, vol. 83, pp. 82-90, 2019.

[3] J. Liu, W. Chen, W. Nie, J. Yuan, and J. Dong, "Experimental research on the mass transfer and flow properties of water inrush in completely weathered granite under different particle size distributions," Rock Mechanics and Rock Engineering, vol. 52, no. 7, pp. 2141-2153, 2019.

[4] D. Ma, H. Duan, X. Li, Z. Li, Z. Zhou, and T. Li, "Effects of seepage-induced erosion on nonlinear hydraulic properties of broken red sandstones," Tunnelling and Underground Space Technology, vol. 91, Article ID 102993, 2019.

[5] Y. W. Tsang and P. A. Witherspoon, "The dependence of fracture mechanical and fluid flow properties on fracture roughness and sample size," Journal of Geophysical Research, vol. 88, no. 3, pp. 2359-2366, 1983.

[6] D. Elsworth, "A model to evaluate the transient hydraulic response of three-dimensional sparsely fractured rock masses," Water Resources Research, vol. 22, no. 13, pp. 1809-1819, 1986.

[7] Y. W. Tsang and C. F. Tsang, "Channel model of flow through fractured media," Water Resources Research, vol. 23, no. 3, pp. 467-479, 1987.

[8] R. W. Zimmerman, S. Kumar, and G. S. Bodvarsson, "Lubrication theory analysis of the permeability of rough-walled fractures," International Journal of Rock Mechanics and Mining Science \& Geomechanics Abstracts, vol. 28, no. 4, pp. 325-331, 1991.

[9] Y.-F. Chen, J.-Q. Zhou, S.-H. Hu, R. Hu, and C.-B. Zhou, "Evaluation of Forchheimer equation coefficients for nonDarcy flow in deformable rough-walled fractures," Journal of Hydrology, vol. 529, pp. 993-1006, 2015.

[10] G. Wang, T. M. Mitchell, P. G. Meredith, Y. Nara, and Z. Wu, "Influence of gouge thickness and grain size on permeability of macrofractured basalt," Journal of Geophysical Research: Solid Earth, vol. 121, no. 12, pp. 8472-8487, 2016. 
[11] M. Wang, Y.-F. Chen, G.-W. Ma, J.-Q. Zhou, and C.-B. Zhou, "Influence of surface roughness on nonlinear flow behaviors in 3D self-affine rough fractures: 1," Advances in Water Resources, vol. 96, pp. 373-388, 2016.

[12] J.-Q. Zhou, M. Wang, L. Wang, Y.-F. Chen, and C.-B. Zhou, "Emergence of nonlinear laminar flow in fractures during shear," Rock Mechanics and Rock Engineering, vol. 51, no. 11, pp. 3635-3643, 2018.

[13] Z. Zhang, J. Nemcik, Q. Qiao, and X. Geng, "A model for water flow through rock fractures based on friction factor," Rock Mechanics and Rock Engineering, vol. 48, no. 2, pp. 559-571, 2015.

[14] L. Zou, L. Jing, and V. Cvetkovic, "Roughness decomposition and nonlinear fluid flow in a single rock fracture," International Journal of Rock Mechanics and Mining Sciences, vol. 75, pp. 102-118, 2015.

[15] J. Wang, . Li, L. Li, and C. Gao, "Influence of fracture characters on flow distribution under different Reynold numbers," Geomechanics Engineering, vol. 14, no. 2, pp. 187-193, 2018.

[16] S. Zhang, W. Qiao, Y. Wu, Z. Fan, and L. Zhang, "Experimental study on seepage characteristics of microfracture with different aperture," Scientific Reports, vol. 10, no. 1, p. 5452, 2020.

[17] X. Qian, C. Xia, and Y. Gui, "Quantitative estimates of nonDarcy groundwater flow properties and normalized hydraulic aperture through discrete open rough-walled joints," International Journal of Geomechanics, vol. 18, no. 9, Article ID 04018099, 2018.

[18] H. Zhou and H. Xie, "Anisotropic characterization of rock fracture surfaces subjected to profle analysis," Physics Letters A, vol. 325, no. 5-6, pp. 355-362, 2004.

[19] Q. Zhang, S. Luo, H. Ma, X. Wang, and J. Qian, "Simulation on the water flow affected by the shape and density of roughness elements in a single rough fracture," Journal of Hydrology, vol. 573, pp. 456-468, 2019.

[20] X. Zhang, Q. Jiang, P. H. S. W. Kulatilake, F. Xiong, C. Yao, and Z. Tang, "Influence of asperity morphology on failure characteristics and shear strength properties of rock joints under direct shear tests," International Journal of Geomechanics, vol. 19, no. 2, Article ID 04018196, 2019.

[21] Y. Ju, J. Dong, F. Gao, and J. Wang, "Evaluation of water permeability of rough fractures based on a self-affine fractal model and optimized segmentation algorithm," Advances in Water Resources, vol. 129, pp. 99-111, 2019.

[22] Z. Dou, B. Sleep, H. Zhan, Z. Zhou, and J. Wang, "Multiscale roughness influence on conservative solute transport in selfaffine fractures," International Journal of Heat and Mass Transfer, vol. 133, pp. 606-618, 2019.

[23] Y. Ge, P. H. S. W. Kulatilake, H. Tang, and C. Xiong, "Investigation of natural rock joint roughness," Computers and Geotechnics, vol. 55, pp. 290-305, 2014.

[24] Y. Li and R. Huang, "Relationship between joint roughness coefficient and fractal dimension of rock fracture surfaces," International Journal of Rock Mechanics and Mining Sciences, vol. 75, pp. 15-22, 2015.

[25] F. Du, G. Jiang, and Z. Chen, “A numerical simulation study of the migration law of water-sand two-phase flow in broken rock mass," Geofluids, vol. 2018, Article ID 6418476, 12 pages, 2018.

[26] Y. Liu, Y. Han, Q. Zhang, M. Li, and Z. F. Wang, "Analysis of water and sand seepage characteristics in fracture," Journal of China Coal Society, vol. 44, no. 3, pp. 874-880, 2019.
[27] W. Sui, J. Liu, B. Gao, and Y. Liang, "A review on disaster mechanism of quicksand with a high potential energy due to mining and its prevention and control," Journal of China Coal Society, vol. 44, no. 8, pp. 2419-2426, 2019.

[28] D. Ma, H. Duan, J. Liu, X. Li, and Z. Zhou, "The role of gangue on the mitigation of mining-induced hazards and environmental pollution: an experimental investigation," The Science of the Total Environment, vol. 664, pp. 436-448, 2019.

[29] Q. Liu and B. Liu, "Experiment study of the failure mechanism and evolution characteristics of water-sand inrush geo-hazards," Applied Sciences, vol. 10, no. 10, p. 3374, 2020.

[30] Y. Hu, W. Li, Q. Wang, S. Liu, and Z. Wang, "Evolution of floor water inrush from a structural fractured zone with confined water," Mine Water and the Environment, vol. 38, no. 2, pp. 252-260, 2019.

[31] Y. Liu and S. Li, Influence of Particle Size On Non-Darcy Seepage Of Water And Sand In Fractured Rock, Vol. p, Springerplus, New York, NY, USA, 2016.

[32] Y.-J. Kim, N.-S. Woo, Y.-K. Hwang, J.-H. Kim, and S.-M. Han, "Transport of small cuttings in solid-liquid flow with inclined slim hole annulus," Journal of Mechanical Science and Technology, vol. 28, no. 1, pp. 115-126, 2014.

[33] L. Fan and S. Liu, "Evaluation of permeability damage for stressed coal with cyclic loading: an experimental study," International Journal of Coal Geology, vol. 216, Article ID 103338, 2019.

[34] Z. Hu, J. Klaver, J. Schmatz et al., "Stress sensitivity of porosity and permeability of Cobourg limestone," Engineering Geology, vol. 273, Article ID 105632, 2020.

[35] M. Duan, C. Jiang, Q. Gan, M. Li, and K. Peng, "Experimental investigation on the permeability, acoustic emission and energy dissipation of coal under tiered cyclic unloading," Journal of Natural Gas Science and Engineering, vol. 73, Article ID 10305, 2020.

[36] Y. Liu, S. Li, L. Ma, and N. Zhou, "Experimental study on nonDarcy seepage of water and sand in fractured rock," Journal of China Coal Society, vol. 43, no. 8, pp. 2296-2303, 2018.

[37] P. Xie, Z. Gao, C. Li et al., "Conductivity of hydraulic fracturing in tight carbonate intra-platform shoal reservoirs," Journal of Petroleum Science and Engineering, vol. 189, Article ID 106976, 2020.

[38] H. Huang, T. Babadagli, H. Li, K. Develi, and G. Wei, "Effect of injection parameters on proppant transport in rough vertical fractures: an experimental analysis on visual models," Journal of Petroleum Science and Engineering, vol. 180, pp. 180-395, 2019.

[39] Y. Zhang and J. Chai, "Effect of surface morphology on fluid flow in rough fractures: a review," Journal of Natural Gas Science and Engineering, vol. 79, Article ID 103343, 2020.

[40] Y. Hu, W. Xu, L. Zhan, J. Li, and Y. Chen, "Quantitative characterization of solute transport in fractures with different surface roughness based on ten Barton profiles," Environmental Science and Pollution Research, vol. 27, no. 12, pp. 13534-13549, 2020.

[41] S. Peng, K. Zhang, L. Fan, J. Kang, K. Peng, and F. Wang, "Permeability reduction and electrochemical impedance of fractured rock grouted by microbial-induced calcite precipitation," Geofluids, vol. 2020, Article ID 8876400, 11 pages, 2020.

[42] C. Yu and D. Li, "Heterogeneity characteristics of flow and transport fields through rough-walled fractures," European Journal of Environmental and Civil Engineering, vol. 22, no. 5, pp. 614-627, 2018. 
[43] T. W. Teklu, X. Li, Z. Zhou, and H. Abass, "Experimental investigation on permeability and porosity hysteresis of tight formations," SPE Journal, vol. 23, no. 3, pp. 672-690, 2018.

[44] Y. Liu, G. Yin, D. Zhang et al., "Directional permeability evolution in intact and fractured coal subjected to true-triaxial stresses under dry and water-saturated conditions," International Journal of Rock Mechanics and Mining Sciences, vol. 119, pp. 22-34, 2019.

[45] T. Chen, X.-T. Feng, G. Cui, Y. Tan, and Z. Pan, "Experimental study of permeability change of organic-rich gas shales under high effective stress," Journal of Natural Gas Science and Engineering, vol. 64, pp. 1-14, 2019. 